\title{
Reproducibility of cardiac output measurement by cross sectional and Doppler echocardiography
}

\author{
STEPHEN C ROBSON, * ALAN MURRAY, † IAN PEART, * ALISON HEADS, * \\ STEWART HUNTER *
}

From the Departments of * Paediatric Cardiology and $\nmid$ Medical Physics, Freeman Hospital, Nerwcastle upon Tyne

SUMMARY The variability of Doppler echocardiographic estimation of cardiac output at the aortic $\circlearrowleft$ orifice was investigated in eight healthy subjects. Cross sectional echocardiograms of the aortic ${ }^{\circ}$ orifice and aortic Doppler velocities were recorded and measured by four echocardiographers. $\infty^{\infty}$ Between subject variability was significantly larger than within subject variability for all variables.윽 Variability owing to different echocardiographers and different measurement times was small $\rightarrow$ compared with total variability. Coefficients of variation for aortic annular diameter, aortic velocity $气$ integral, and heart rate were $4 \cdot 1 \%, 6 \cdot 4 \%$, and $5 \cdot 0 \%$ respectively. The coefficient of variation for $\widehat{\varnothing}$ cardiac output was $8 \cdot 8 \%$ and the $95 \%$ confidence interval for measurement of cardiac output by the $\vec{\oplus}$ Doppler method was 4.45 to $6.35 \mathrm{l} / \mathrm{min}$. One echocardiographer reanalysed all the recordings and $\infty$ the results showed that recording the echocardiograms introduces a significantly larger source of error than measuring them.

Thus serial measurements of cardiac output by the Doppler method can be performed with acceptable reproducibility; this indicates that the technique can be accurately applied in clinical practice.

Cardiac output can be calculated from the blood velocity in the ascending aorta (measured by Doppler ultrasound) combined with aortic orifice area (measured by cross sectional echocardiography). The technique has been validated in various laboratory and clinical situations $\mathrm{s}^{1-3}$ and provides a simple and reliable method for the measurement of cardiac output without the need for vascular catheterisation.

To interpret Doppler flow measurements in clinical practice it is necessary to establish the variability of velocity and area measurements. Several studies have reported the variability of aortic velocity measurements, ${ }^{4-6}$ but the variability of calculated cardiac output has been inadequately reported. This study investigated the variability of cardiac output measurement across the aortic valve in normal subjects. The contribution of the various sources of imprecision to the overall variability was determined

Requests for reprints to Dr Stewart Hunter, Department of Paediatric Cardiology, Freeman Hospital, High Heaton, Newcastle upon Tyne NE7 7DN.

Accepted for publication 22 September 1987 and the $95 \%$ confidence interval for a single observation was estimated.

\section{Patients and methods}

Eight healthy people (six men, two women) aged 22-3. 52 years (mean 28 years) were investigated. The procedure was explained to each subject and their $₹$ informed consent was obtained. Measurements were $\mathrm{o}$ made with the subjects in the semirecumbent position after they had rested for at least 15 minutes in a음 warm, quiet room. Cross sectional echocardiograms $\frac{\mathrm{N}}{\mathrm{N}}$ and continuous wave Doppler recordings were made $\mathrm{N}$ on a Hewlett-Packard system (Model 77020A) with a N 3.5 $\mathrm{MHz}$ phased array transducer and a $1.9 \mathrm{MHz}$ dedicated independent continuous wave transducer. 0 Recordings were made by four experienced

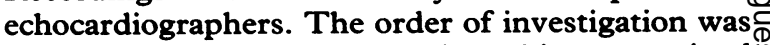
randomised using a LS and the subjects remained $\stackrel{S}{+}$ recumbent throughout.

The diameter of the aortic orifice was measuredo during systole from cross sectional echocardiograms in the parasternal long axis plane. ${ }^{7}$ Echocardiograms $\frac{\mathbb{Q}}{\alpha}$ were recorded on videotape and then measured after $\bar{O}$ completion of the velocity recordings by a freeze 
frame facility with superimposed calipers. Measurements were made from the leading edge of the anterior wall to the leading edge of the posterior wall. The diameters from five consecutive beats were averaged and the cross sectional area (CSA) was calculated from the equation $\Pi \times(\mathrm{D} / 2)^{2}$, where $\mathrm{D}=$ mean aortic diameter.

Blood velocity in the ascending aorta was recorded from the suprasternal notch by continuous wave Doppler ultrasonography. The direction of the ultrasound beam was adjusted until the highest velocities with the "cleanest" envelope were obtained. These velocities were taken to represent the velocities at the aortic orifice when the ultrasound beam was parallel with flow. The Doppler output and an electrocardiographic tracing were recorded on a strip chart at a paper speed of $100 \mathrm{~mm} / \mathrm{s}$. The area under the velocity curve, or the velocity integral (VI), was determined after each investigation by tracing from the baseline around the maximum velocity curve with a digitising tablet linked to a microcomputer. ${ }^{8}$ Ten consecutive beats were averaged for each measurement.

Heart rate (HR) was measured directly from the $R R$ interval of the simultaneously recorded electrocardiogram. Stroke volume (SV) and cardiac output (CO) were calculated as follows:

$$
\begin{gathered}
\mathrm{SV}(\mathrm{ml})=\mathrm{VI}(\mathrm{cm}) \times \mathrm{CSA}\left(\mathrm{cm}^{2}\right), \mathrm{CO}(1 / \mathrm{min})= \\
\mathrm{SV}(\mathrm{ml}) \times \mathrm{HR}\left(\mathrm{min}^{-1}\right) \div 1000 .
\end{gathered}
$$

The observers analysed their own recordings. Heart rate and velocity recordings were then numbered and reanalysed blindly out of order by one observer (SCR) to measure intraobserver variability. Because cross sectional echocardiograms were stored on videotape it was not possible to reanalyse them in random order. To try to eliminate any possible observer bias, recordings were reanalysed several weeks after the initial investigation.

\section{STATISTICAL ANALYSIS}

An analysis of variance was used to determine the contribution of various factors (variance components) to the overall variance. The total variance consists of a component owing to differences between the subjects $\left(\sigma \mathrm{s}^{2}\right)$ and a component owing to differences within subjects $\left(\sigma \mathbf{w}^{2}\right)$. The within subject variance is made up of a component representing the variability between echocardiographers $\left(\sigma \mathrm{E}^{2}\right)$, a temporal component representing the variability between measurement times $\left(\sigma \mathrm{T}^{2}\right)$, and a component representing the residual variability $\left(\sigma R^{2}\right)$. An approximate $95 \%$ confidence interval for a particular measurement on a typical subject was calculated as mean $\pm 2 \sigma \mathrm{w}$. The confidence intervals calculated in this way relate specifically to the method used in this study which gives an average over a given number of cardiac cycles to reduce some of the within subject variability attributable to measurements from individual cardiac cycles. Coefficients of variation were determined from the within patient variance as $\sigma \mathrm{w} \div$ mean .

An estimate of the contributions to the total variance of recording and of measuring the echocardiogram was obtained by calculating the differences between the initial measurements (performed by the four echocardiographers) and the repeat measurements (performed by one echocardiographer) for all recordings of the velocity integral, heart rate, and diameter. The variance attributable to measuring an echocardiogram was estimated from the standard deviation of the differences. This variance was then subtracted from the total variance for an estimate of the variance caused by the recording of the echocardiogram.

\section{Results}

Satisfactory diameter and velocity recordings were obtained in all eight subjects by each of the four echocardiographers. Investigations were completed in less than 30 minutes in each subject. Calculated Doppler cardiac output ranged from $4.591 / \mathrm{min}$ to $6.50 \mathrm{l} / \mathrm{min}$.

Figure 1 shows the variance components for heart rate, velocity integral, and aortic diameter. Figure 2 shows the variance components for the calculated

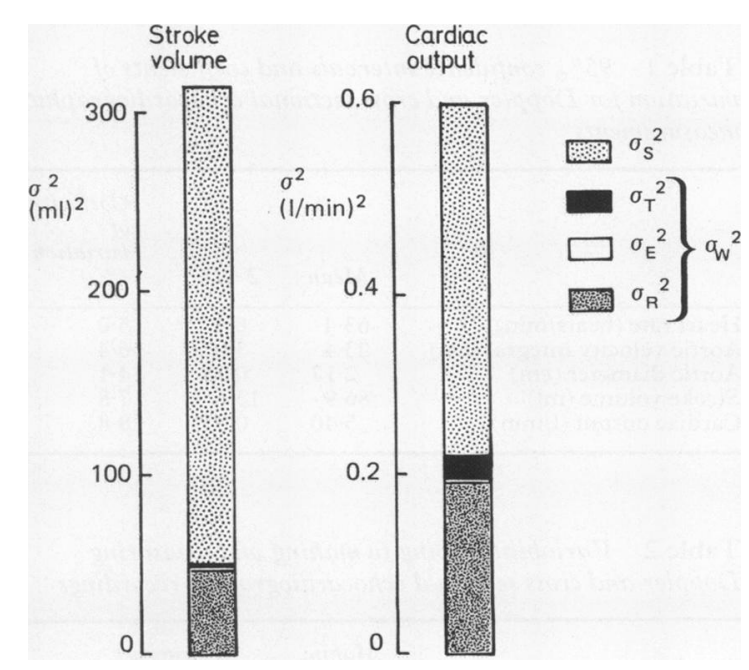

Fig 1 Variance components for heart rate, velocity integral, and aortic diameter. $\sigma \mathrm{s}^{2}$, between subject component; $\sigma \mathrm{w}^{2}$, within subject component; $\sigma \mathrm{T}^{2}$, temporal component; $\sigma \mathrm{E}^{2}$, echocardiographer component; $\sigma \mathrm{R}^{2}$, residual component. See text for explanation. 
Fig 2 Variance components for stroke volume and cardiac output. $\sigma \mathrm{s}^{2}$, between subject component; $\sigma \mathrm{W}^{2}$, within subject component; $\sigma \mathrm{T}^{2}$, temporal component; $\sigma \mathrm{E}^{2}$, echocardiographer component; $\sigma \mathrm{R}^{2}$, residual component. See text for explanation.

variables stroke volume and cardiac output. For all variables the within subject variance was significantly smaller than the between subject variance $(p<$ $0.001)$. The "between echocardiographer" variance $\left(\sigma \mathrm{E}^{2}\right)$ and the "between measurement times" variance

Table $195 \%$ confidence intervals and coefficients of variation for Doppler and cross sectional echocardiographic measurements

\begin{tabular}{|c|c|c|c|}
\hline & Mean & $2 S D$ & $\begin{array}{l}\text { Coefficient } \\
\text { of } \\
\text { variation } \\
(\%)\end{array}$ \\
\hline $\begin{array}{l}\text { Heart rate (beats } / \mathrm{min}) \\
\text { Aortic velocity integral }(\mathrm{cm}) \\
\text { Aortic diameter }(\mathrm{cm}) \\
\text { Stroke volume }(\mathrm{ml}) \\
\text { Cardiac output }(1 / \mathrm{min})\end{array}$ & $\begin{array}{l}63 \cdot 4 \\
23 \cdot 4 \\
2 \cdot 17 \\
86 \cdot 9 \\
5 \cdot 40\end{array}$ & $\begin{array}{c}6 \cdot 4 \\
3 \cdot 0 \\
0 \cdot 18 \\
13 \cdot 6 \\
0.95\end{array}$ & $\begin{array}{l}5 \cdot 0 \\
6 \cdot 4 \\
4 \cdot 1 \\
7 \cdot 8 \\
8 \cdot 8\end{array}$ \\
\hline
\end{tabular}

Table 2 Variability owing to making and measuring Doppler and cross sectional echocardiographic recordings

\begin{tabular}{llll}
\hline & $\begin{array}{l}\text { Makis } \\
\text { echo }(S D)\end{array}$ & $\begin{array}{l}\text { Measuring } \\
\text { echo }(S D)\end{array}$ & $p$ \\
\hline Heart rate (beats/min) & 3.1 & 0.4 & $<0.001$ \\
Aortic velocity integral (cm) & 1.3 & 0.7 & $<0.001$ \\
Aortic diameter (cm) & 0.07 & 0.05 & $<0.05$ \\
Stroke volume (ml) & 5.0 & 4.6 & $\mathrm{NS}$ \\
Cardiac output (1/min) & 0.40 & 0.27 & $<0.025$ \\
\hline
\end{tabular}

$\left(\sigma \mathrm{T}^{2}\right)$ were both small for all the measured and calculated variables and in no case were they significantly different from the residual variance $\left(\sigma \mathrm{R}^{2}\right)$. $\stackrel{\mathbb{Q}}{\varrho}$ The calculated within subject components shown in $\overrightarrow{\vec{P}}$

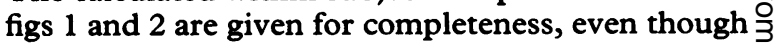
there were no significant differences.

Table 1 shows the mean and approximate $95 \%$ confidence intervals for each variable. Table 2 shows the contribution of recording and measuring the $\mathbb{\mathbb { D }}$ echocardiograms to the total within subject variance. The variance owing to recording the echocardiogram was significantly larger than the variance owing to measuring recordings for all variables except stroke volume. The variability of the one analyser who reanalysed his own recordings (intraobserver variability) was compared with the variability of the $\frac{7}{0}$ same analyser analysing the recordings of the other three analysers (interobserver variability) and no $\mathrm{N}$ significant differences were found except for the $N$ measurement of velocity integral $(p<0.005)$.

\section{Discussion}

This study reports the variability of Doppleros measurements of aortic flow in a group of healthy adults. The echocardiographers were all experiencedo in obtaining and analysing Doppler velocity and $\vec{\Phi}$ cross sectional recordings and no attempt was madeêे to select good echocardiographic subjects. Thus we hoped that the study would determine the size and 
source of error that might be expected in clinical practice.

We used a components-of-variance analysis to estimate the different possible sources of imprecision for each of the measurements. The results suggest that the variability caused by different observers obtaining and measuring echocardiographic recordings is small relative to the total variability. The variance owing to differences between the measurement times was also very small. By having one observer reanalyse all the recordings we were also able to determine that recording the echocardiograms is a significantly larger source of error than measuring them.

We believe that the present study is the first to report the reproducibility of measurement of aortic cardiac output by continuous wave Doppler. Lewis et al studied the interobserver reproducibility of measuring aortic flow by pulsed Doppler from the cardiac apex. ${ }^{9}$ They reported a mean (SD) percentage error (difference between paired measurements expressed as a percentage of the mean of the pair) between the two observers of $6.8(5.0) \%$ for aortic stroke volume and cardiac output. With two observers, Ihlen et al obtained aortic continuous wave velocity recordings on two occasions one to 21 days apart. ${ }^{10}$ All the recordings were then analysed by both observers. Aortic diameter was measured only once and this value was used for all later stroke volume calculations. The coefficient of variation between any pair of.measurements in each patient was $9 \cdot 2 \%$, which is similar to that found in the present study. The coefficient of variation between the two observers was $0.1 \%$ and between the two measurement times it was $0.9 \%$, confirming that interobserver and temporal variability contribute little to the overall variability.

Several previous studies have investigated the reproducibility of measurements of the velocity integral obtained from aortic continuous wave Doppler traces. Most studies have reported interobserver, intraobserver, and day to day variability, whether expressed as a mean percentage error or as a coefficient of variation, to be less than $6 \% .{ }^{5611}$ Comparable figures have been reported for heart rate measurements. ${ }^{612}$ The results of the present study are consistent with these findings.

Although several workers have investigated the change in aortic diameter during the cardiac cycle ${ }^{1314}$ this is the first study to report the variability of measurements of aortic annular diameter. Meijboom et al, in a study of Doppler mitral flow measurement, reported comparable variability for measurements of mitral diameter. ${ }^{15}$ These findings suggest that although cross sectional echocardiographic diameter measurements are very reproducible, they are the largest source of error in Doppler flow measurements because the diameter has to be squared to obtain cross sectional area for flow calculation (the coefficient of variation for aortic area in the present study was $8.3 \%$ ).

Probably the most clinically useful measure of reproducibility is the $95 \%$ confidence interval for a single measurement. This quantitates the size of change in an individual subject that is likely to represent a true haemodynamic change. Thus when different observers study unselected subjects, changes in cardiac output of more than $11 / \mathrm{min}$ cannot be accounted for by the variability inherent in the technique and are likely to represent a genuine change in cardiac output. This result resembles measurement of cardiac output by the dye dilution and thermodilution methods. ${ }^{16}{ }^{17}$ Satisfactory recordings were obtained in all subjects in the present study. Most previous studies have reported acceptable recordings in over $80 \%$ of patients with heart disease ${ }^{118}$ although this fell to approximately $70 \%$ in ill patients undergoing haemodynamic monitoring in intensive care. ${ }^{319}$ Nevertheless, in those subjects in whom satisfactory recordings are possible the Doppler method provides a simple, quick, and noninvasive technique for measuring cardiac output. The present results indicate that serial measurements, even if performed by different observers, are sufficiently reproducible to be useful in clinical practice.

\section{References}

1 Huntsman LL, Stewart DK, Barnes SR, Franklin SB, Colocousis MD, Hessel EA. Noninvasive Doppler determination of cardiac output in man: clinical validation. Circulation 1983;67:593-602.

2 Rose JS, Nanna M, Rahimtoola SH, Elkayam U, McKay C, Chandraratna PAN. Accuracy of determination of changes in cardiac output by transcutaneous continuous wave Doppler computer. Am J Cardiol 1984;54:1099-101.

3 Nishimura RA, Callaghan MJ, Schaff HV, Ilstrup DM, Miller FA, Tajik AK. Noninvasive measurement of cardiac output by continuous wave Doppler echocardiography: initial experience and review of the literature. Mayo Clin Proc 1984;59:484-9.

4 Brubakk AO, Gisvold SE. Pulsed Doppler ultrasound for measuring blood flow in the human aorta. In: Hatle L, Angelsen B, eds. Doppler ultrasound in cardiology. Physical principles and clinical application. Philadelphia: Lea and Fabiger, 1982:185-93.

5 Gardin JM, Debestani A, Matin K, Allfie A, Russell D, Henry WL. Reproducibility of Doppler aortic blood flow measurements: studies on intraobserver, interobserver and day-to-day variability in normal subjects. Am J Cardiol 1984;54:1092-8.

6 McLennan FM, Haites NE, Mackenzie JD, 
Daniel MK, Rawles JM. Reproducibility of linear cardiac output measurement by Doppler ultrasound alone. Br Heart $J$ 1986;55:25-31.

7 Ihlen H, Amlie JP, Dale J, et al. Determination of cardiac output by Doppler echocardiography. $\mathrm{Br}$ Heart J 1984;51:54-60.

8 Goldberg SJ, Allen HD, Marx GR, Flinn CJ. Doppler echocardiography. Philadelphia: Lea and Fabiger, 1985:80.

9 Lewis J, Lawrence CK, Nelson JG, Limacher MC, Quinones MA. Pulsed Doppler echocardiographic determination of stroke volume and cardiac output: clinical validation of two new methods using the apical window. Circulation 1984;70:425-31.

10 Ihlen H, Endresen K, Myreng Y, Myhre E. Reproducibility of cardiac stroke volume estimated by Doppler echocardiography. Am J Cardiol 1987;59:975-8.

11 Fraser CB, Light LH, Shinebourne EA, Buchtal A, Healy MJR, Beardshaw JA. Transcutaneous aortovelography: reproducibility in adults and children. Eur J Cardiol 1976;4:181-9.

12 Kupari M. Reproducibility of M-mode echocardiographic assessment of left ventricular function: significance of temporal range of measurements. Eur Heart $J$ 1984;5:412-8.

13. Greenfield JC, Patel DJ. Relation between pressure and diameter in the ascending aorta of man. Circ Res 1962;10:778-81.

14 Gardin JM, Tobis JM, Debestani A, et al. Superiority of two-dimensional measurement of aortic vessel on diameter in Doppler echocardiographic estimates of $\bar{O}$ left ventricular stroke volume. $\mathrm{J} \mathrm{Am}$ Coll Cardiol 1985;6:66-74.

15 Meijboom EJ, Rijsterborgh H, Bot H, De Boo JAJ, Roelandt JRTC, Bom N. Limits of reproducibility of $\varnothing$ blood flow measurements by Doppler echocardiogra- के phy. Am J Cardiol 1987;59:133-7.

16 Stetz CW, Miller RG, Kelly GE, Raffin TA. Reliability of the thermodilution method in the determination of cardiac output in clinical practice. Am Rev Respir Dis 1982;126:1001-4.

17 Schuster AH, Nanda NC. Doppler echocardiographic measurement of cardiac output: comparison with a non-golden standard. Am J Cardiol 1984;53:257-9.

18 Chandraratna PA, Nanna M, McKay C, et al. D Determination of cardiac output by transcutaneous continuous wave ultrasonic Doppler computer. $\mathrm{Am} \mathrm{J}$ Cardiol 1984;53:234-7.

19 Vandenbogaerde JF, Scheldewaert RG, Rijckaert DL, Clement DL, Colardyn FA. Comparison between $\overparen{\Phi}$ ultrasonic and thermodilution cardiac output $\vec{\bullet}$ measurements in intensive care patients. Crit Care $\infty$ Med 1986;14:294-7. 